\title{
Pharmaceutical Quality/CMC Drug Substance Product Indicator Terminology
}

National Cancer Institute

\section{Source}

National Cancer Institute. Pharmaceutical Quality/CMC Drug Substance Product Indicator

Terminology. NCl Thesaurus. Code C133855.

A category of terminology used to qualify the information pertaining to drug substances

product indicators in the framework of the Pharmaceutical Quality/Chemistry,

Manufacturing and Controls documents. 